\title{
What catches the eye in class observation? Observers' perspectives in a multidisciplinary peer observation of teaching program
}

\author{
Ana Cristina Torres, Amélia Lopes , Jorge M. S. Valente \& Ana Mouraz
}

To cite this article: Ana Cristina Torres, Amélia Lopes, Jorge M. S. Valente \& Ana Mouraz (2017) What catches the eye in class observation? Observers' perspectives in a multidisciplinary peer observation of teaching program, Teaching in Higher Education, 22:7, 822-838, DOI: 10.1080/13562517.2017.1301907

To link to this article: http://dx.doi.org/10.1080/13562517.2017.1301907

\section{曲 Published online: 15 Mar 2017.}

\section{Submit your article to this journal $\longleftarrow$}

Џ Article views: 181

Q View related articles ¿

View Crossmark data ¿ 


\title{
What catches the eye in class observation? Observers' perspectives in a multidisciplinary peer observation of teaching program
}

\author{
Ana Cristina Torres ${ }^{a}$, Amélia Lopes ${ }^{a}$, Jorge M. S. Valente ${ }^{b}$ and Ana Mouraz ${ }^{a}$ \\ ${ }^{\mathrm{a}}$ Faculty of Psychology and Education Sciences, University of Porto, Centre for Research and Intervention in \\ Education (CIIE), Porto, Portugal; ${ }^{b}$ Faculty of Economics, University of Porto, LIAAD - INESC TEC, Porto, \\ Portugal
}

\begin{abstract}
Peer Observation of Teaching has raised a lot of interest as a device for quality enhancement of teaching. While much research has focused on its models, implementation schemes and feedback to the observed, little attention has been paid to what the observer actually sees and can learn from the observation. A multidisciplinary peer observation of teaching program is described, and its data is used to identify the pedagogical aspects to which lecturers pay more attention to when observing classes. The discussion addresses the valuable learning opportunities for observers provided by this program, as well as its usefulness in disseminating, sharing and clarifying quality teaching practices. The need for further research concerning teacher-student relationships and students' engagement is also suggested.
\end{abstract}

\section{ARTICLE HISTORY}

Received 29 August 2016

Accepted 20 February 2017

\section{KEYWORDS}

Multidisciplinary peer observation of teaching; class observation; observer; teaching practices; pedagogies

\section{Introduction}

Peer Observation of Teaching (POT) has raised a lot of interest as a device for faculty professional development and university/department quality enhancement of teaching. It raises awareness of teaching in higher education as 'a matter of collective responsibility' (Gosling 2002, 4), by diminishing the pedagogical solitude of the teaching profession, enhancing the collegiality and scholarly approach to teaching in academic staff, fostering the dissemination of the best teaching practices and promoting reflection (Bell and Mladenovic 2015; Cosh 1998; Gosling 2000, 2002; Hammersley-Fletcher and Orsmond 2004, 2005; Martin and Double 1998; Hendry, Bell, and Thomson 2014; Martsolf et al. 1999). Gosling (2005) distinguished three POT models differing on observer objectives, position and status of the provided evidence: the evaluation model, the professional development model and the collaborative model. While the evaluation model tries to produce judgements on teaching practices, the other models are mainly aimed at their improvement. In the evaluation model, senior staff observe other staff and produce judgements with consequences (or not) in the professional promotion of the observed teachers. The professional development model proposes that educational developers or expert teachers 
observe the less experienced ones, from which they produce improvement suggestions. In the collaborative model, the observer is frequently a peer who is also observed (Yiend, Weller, and Kinchin 2014). Thus, along with the observation, lecturers discuss and mutually reflect in a non-judgmental environment, both learning and developing themselves with the experience (Hammersley-Fletcher and Orsmond 2004).

This emphasis on POT programs and their formative potential brought new important discussions with it, such as the ones concerning advantages and disadvantages of disciplinary or multidisciplinary nature of the programs and the impact of observation itself to the professional development of the observer.

The first one relates with the traditional importance of contents in higher education teaching practices and organizational/disciplinary cultures. That's one of the reasons why, for example, Tenenberg (2014) argued that learning can only happen when observer and observed teach the same subjects. The second one comes from reported benefits, at an individual level, for both observer and observed (Kohut, Burnap, and Yon 2007). While the value of POT as promoter of the observer's active self-development (Cosh 1998) and learning (Hendry, Bell, and Thomson 2014; Tenenberg 2014) has been demonstrated, little attention has been paid to what is actually seen by the observers (Thomson, Bell, and Hendry 2015), thought often that is precisely the object of reflection and learning and the starting point for changes that result in improved teaching practices. This is the focus of this paper. Using data from a Multidisciplinary POT (MPOT) program with a collaborative model, ongoing at the University of Porto since 2011, it is described 'what is seen' by lecturers that play the role of observers, aiming to highlight the pedagogical aspects to which lecturers pay more attention to when observing classes and whether there are differences in that attention according to the observer's disciplinary field.

The theoretical framework is first presented, focusing on multidisciplinary peer observation of teaching and on the value of playing the role of observer to professional development of teachers. Afterwards, details of the MPOT program ongoing at the University of Porto, and of the methodology of the study - grounding on data from the observation forms filled by observers since 2011, and from interviews conducted in 2014 - are also presented and followed by the main findings and their discussion.

\section{Multidisciplinary peer observation of teaching}

Quality teaching is a highly complex concept, constantly changing with society and students' demands. Nowadays, after a recognition of the importance of students' motivation and independent learning (Knight and Trowler 2000), emphasis has increasingly been put in providing students with flexible skills and in developing positive teacher-student interactions (Hénard 2010), mainly due to the benefits to students' engagement and achievement (Coates 2005; Hagenauer and Volet 2014). These notions have been expanded by the pedagogic/curricular reforms driven by the Bologna process and the consequent need to transform higher education classes in more student-centered, interactive and flexible learning environments.

Peer observation of teaching can play a vital role in defining institutional outlines of quality teaching (Hammersley-Fletcher and Orsmond 2005) that stand by these shifting trends and in documenting and disseminating achievements of effective teaching 
(Kohut, Burnap, and Yon 2007). It can also routinize collaboration among academic staff in order to foster cultural changes that promote quality teaching (Knight and Trowler 2000; Lomas and Nicholls 2005). And though arguing that focus should be more on the qualities of a good teacher, and less on the quality of teaching, Cosh (1998) defended that POT can help teachers become more self-aware, self-critical, open-minded, confident, and passionate and have a sense of professional worth and be willing to try new approaches, such as the ones demanded by the paradigm shift to a learning approach. This is why a considerable amount of research has explored the features of POT that better encourage collaboration and reflective practices.

One of these features concerns its same discipline versus different discipline structure. Although it has been argued that POT must occur within the same discipline to actually promote learning (Tenenberg 2014) due to teaching practices deeply rooted in departmental-level cultures (Knight and Trowler 2000), it can be precisely this disciplinary focus that sometimes hinders deep reflection about teaching practices (HammersleyFletcher and Orsmond 2005) and prevents teachers 'to become aware of differences that depend on specificities of the fields of knowledge or academic departments to which they belong' (Mouraz, Lopes, and Martins Ferreira 2013). Observations within the same disciplines or departments can be valuable in making teachers aware of their framing in a disciplinary culture and facilitate the identification of specific problems in a familiar context that are difficult to be identified when playing the role of teacher (Tenenberg 2014). But can also jeopardize true collaboration among observer and observed due to unbalanced power relationships and sense of losing control of the POT experience (McMahon, Barrett, and O’Neill 2007). To avoid these risks, Tenenberg (2014) proposed that same discipline class observations occurred between teachers from different institutions. However, observations in a different discipline may favor constructive and critical feedback, not only by helping lecturers to escape constraints raised by fear of prejudice of personal relationships (Hammersley-Fletcher and Orsmond 2005), but also by reducing the focus on the contents being taught (Kinchin 2005). When the focus on contents is removed, the different degrees of subject expertise held by observer and observed can be set aside, making the process of peer observation more collaborative and balanced while also favoring an increased attention to students' engagement and learning, in line with the intended paradigm shift of recent trends in higher education teaching (Coates 2005; Hagenauer and Volet 2014; Hénard 2010). Furthermore, it can also make lecturers consider new ways of thinking and behaving within disciplinary fields other than their own.

In the University of Porto, the option has been for a multidisciplinary model of peer observation of teaching in which observations are not restricted to this debate. Instead they are operationalized by having each participant's class observed by one lecturer of the same faculty and another lecturer of a different faculty. Reflection on the observation is thus enriched by confronting a view from a closer field of knowledge and a view from a distant field of knowledge. This is also why considerable research focuses on ways to optimize feedback to foster reflection. Some suggestions are pre and post sessions that put the reflective process, meanings and purposes in perspective (Hammersley-Fletcher and Orsmond 2005), and feedback from an educational developer, involved directly or not in the class observations (Bell 2001; Yiend, Weller, and Kinchin 2014). 


\section{The observer in peer observation of teaching}

Few studies have highlighted the importance of the observer and the value of POT for his/her learning. Playing the role of observer has been recognized as fundamental to help one become aware of teacher and student behavior and attitudes, as well as to learn about other ways of being a teacher' (Mouraz, Lopes, and Martins Ferreira 2013 , 378). This can be achieved both in similar and different discipline contexts, as long as the focus of observation is flexible and in areas of interest to both observer and observed (Cosh 1998; McMahon, Barrett, and O'Neill 2007). Specific training in class observation for academic staff to enhance the benefits of POT (HammersleyFletcher and Orsmond 2004; Kohut, Burnap, and Yon 2007) is of major importance, as well as a post-observation task allowing clarification of questions raised in the observation and sharing of good practices.

Tenenberg (2014) presented a theoretical model for observation-based change that explains the observer learning in a POT process by engagement in a "double-seeing" of his/her own classroom in comparison to the classroom that he/she observes' (16), finding convergences and divergences in the teacher actions and subsequent student behavior. Frequently, the observer notices problems that he/she also faces, but are harder to identify when committed to the role of teacher, as well as a solution that can be implemented in his/her own classes.

Hendry, Bell, and Thomson (2014) also described lecturers' reports of learning about teaching practices from their observation experiences, and developing motivation and confidence to use these strategies in their own teaching, since they had the opportunity to watch the students' reactions and level of engagement in their colleagues' teaching situation. Observers were mostly attentive to ways of promoting group discussion or interactivity that enhanced students' engagement. Later, Thomson, Bell, and Hendry (2015) also defended the need to expand the idea of 'just watching', without the formalities commonly applied to POT. Indeed, acting as observers may return agency to academics helping them to develop their own repertoire of teaching practices, without the pressure of accountability or of showing evidence of learning.

\section{Multidisciplinary peer observation of teaching in the University of Porto}

Though seemingly a tradition in higher education institutions across Australia, UK and USA (Lomas and Nicholls 2005; Yiend, Welller, and Kinchin 2014), in Portugal POT practices have only emerged in the past decade (Mouraz, Lopes, and Martins Ferreira 2013; Vieira et al. 2004), fighting constraints related with a well-established tradition of discipline-structured and research-focused universities, that undervalue the teaching profession in academic careers and rarely encourage collaboration among teaching staff and research about higher education pedagogy and one's own teaching practices (Vieira 2005). This shift was largely driven by ongoing curricular and pedagogic reforms boosted by the Bologna process and consequent leadership recognition of the need to promote specific and effective pedagogic training to shift from a teacher-centred to a student-centred paradigm (Veiga and Amaral 2009).

The University of Porto is publicly funded and the second largest Portuguese university by number of enrolled students (31,892 in 2015). It has 14 faculties (Architecture, Arts, 
Biomedical Sciences, Dental Medicine, Economics, Engineering, Fine Arts, Law, Medicine, Nutrition and Food Science, Pharmacy, Psychology and Education Sciences, Sciences and Sports), 1 Business school, 49 research units and 16 libraries, distributed across 3 campuses within the city. It offers 34 bachelor degrees, 18 integrated masters, 124 2nd Bologna cycle masters, 84 doctoral program, and nearly 400 continuous education courses. The university has nearly 2300 teachers and researchers, with over $75 \%$ holding a doctorate and working full-time.

A collaborative and multidisciplinary POT program is ongoing at the university since 2011 (presentation video available at https://youtu.be/_0B). Each semester, an average of 24 lecturers from different faculties have voluntarily participated in the program. Though being a relatively low percentage of the University's teaching staff $(9,6 \%$ female and $4,6 \%$ male), it has remained steady with different participants throughout the years. Groups of four lecturers are organized, with two pairs of lecturers from two different faculties. Each lecturer observes two classes, and is observed at least once, according to the model illustrated in Figure 1.

Sometimes, participants organize the groups themselves. Almost always observed lecturers are encouraged to choose and make clear to the observers the intended focus of observation, allowing for them to choose specific aspects of their practice they wish to improve. This gives them more control over observers, focus and generated data-flow, thus encouraging them to emphasize improvement of practice over demonstration of existing good practice (McMahon, Barrett, and O’Neill 2007).

There is an initial training session, with all participants, in which the details of the MPOT scheme are explained, and clarifications are given regarding observer's role, type of feedback and the importance of post-observation joint reflection. As widely recommended (Hammersley-Fletcher and Orsmond 2005; Martin and Double 1998), each observation cycle involves pre- and post-observation exchanges, in addition to the actual observation. Pre-observation exchanges allow establishing curricular context (course and class information), underlying teacher-student relationships and teacher concerns about the class to be observed. During the lecture, observers take notes according to the observation form, pre-observation agreements and other criteria they consider

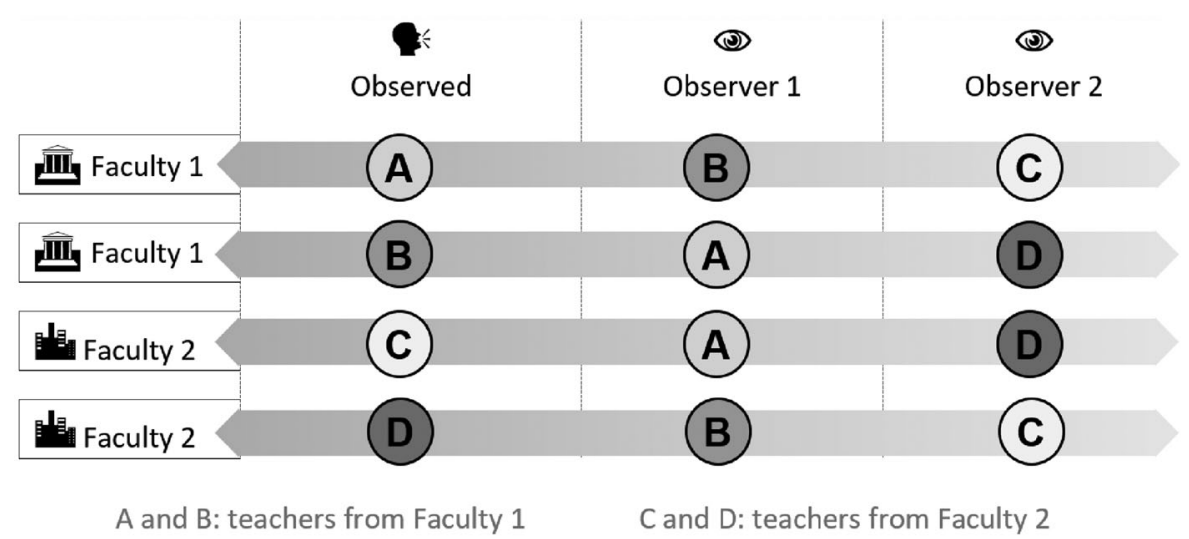

Figure 1. Model of multidisciplinary peer observation of teaching at the University of Porto. 
appropriate. Post-observation meetings emphasize feedback and associated communication skills, in order to foster reflection and professional development (HammersleyFletcher and Orsmond 2005; Mouraz, Lopes, and Martins Ferreira 2013). During and post- observation, the observer is asked to fill, anonymously, a specific observation form that includes four sets of questions, as outlined in Table 1 .

The first set asks for the observer and the observed faculty and gender, as well as course and class information. The second set, to be answered during class observation, asks lecturers to score from 1 (weak) to 5 (strong), when appropriate, several predetermined items in categories of class structure, class organization, class climate, content and teacher's attitude. Observers are instructed to score only the items that apply to the specificities of the

Table 1. Categories and items of the observation form used in the peer observation of teaching (POT) program of the University of Porto (Mouraz, Lopes, and Martins Ferreira 2013).

\begin{tabular}{|c|c|}
\hline Categories & Items \\
\hline \multirow{3}{*}{$\begin{array}{l}\text { Course and class } \\
\text { information }\end{array}$} & Observer faculty and gender \\
\hline & Observed faculty and gender \\
\hline & $\begin{array}{l}\text { Program year, class number, total number of classes in course, time of observation, number of } \\
\text { students in class, classroom capacity, type of class. }\end{array}$ \\
\hline \multirow[t]{4}{*}{ Class structure } & $\begin{array}{l}\text { 1. Clear relation between the class and the learning objectives and competences to be } \\
\text { developed in the course. }\end{array}$ \\
\hline & 2. The learning objectives of the class are clearly identified. \\
\hline & 3. The class structure reflects a logic flow with a beginning, a middle and an end. \\
\hline & 4. Open item to be proposed by observers \\
\hline \multirow[t]{7}{*}{ Class organization } & 1. Adequacy of the space to the developed activities. \\
\hline & 2. Available materials to the developed activities. \\
\hline & 3. Control and management of the learning activities. \\
\hline & 4. Use of available equipment. \\
\hline & 5. Adequacy of the lecture presentation. \\
\hline & 6. Adequacy of the type of work of the students. \\
\hline & 7. Open item to be proposed by observers. \\
\hline \multirow[t]{7}{*}{ Class climate } & 1. Existence of a stimulating learning environment \\
\hline & 2. Existence of collaboration between students. \\
\hline & 3. Existence of participation previously prepared by students. \\
\hline & 4. Promotion of the students' independent, critical or reflective thinking. \\
\hline & $\begin{array}{l}\text { 5. Feedback is given to students about their understanding of concepts or mastery of skills. } \\
\text { 6. Students' involvement in the developed activities. }\end{array}$ \\
\hline & $\begin{array}{l}\text { 7. Appropriateness of the teachers' intervention given the existence of disruptive behaviors } \\
\text { that hinder the class. }\end{array}$ \\
\hline & 8. Open item to be proposed by observers. \\
\hline \multirow[t]{6}{*}{ Content } & 1. Properly challenging content. \\
\hline & 2. Contextualization of content. \\
\hline & 3. Appreciation of the fundamental aspects. \\
\hline & 4. Relationship between content and the students' previous knowledge. \\
\hline & 5. Use of relevant examples. \\
\hline & $\begin{array}{l}\text { 6. Students' participation in the contextualization of content. 7. Open item to be proposed by } \\
\text { observers. }\end{array}$ \\
\hline \multirow[t]{8}{*}{ Teacher's attitude } & 1. Appropriate rhythm. \\
\hline & 2. Attention to the overall dynamic of the class. \\
\hline & 3. Adequate use of voice and gesture. \\
\hline & 4. Individualized interaction with students. \\
\hline & 5. Ability to monitor the progress of students. \\
\hline & 6. Ability to change strategies if the students do not show the expected understanding. \\
\hline & 7. Existence of systematization that contributes to learning. \\
\hline & 8. Open item to be proposed by observers. \\
\hline \multirow[t]{3}{*}{ Other considerations } & -What was most striking? \\
\hline & - What questions would I like to ask to my colleague? \\
\hline & $\begin{array}{l}\text { - What similarities / differences were found in relation to my own lecturing practice? } \\
\text { - Can I make any recommendations? }\end{array}$ \\
\hline Final joint remarks & Appreciation of joint reflection \\
\hline
\end{tabular}


type of class they are observing and can also include new items, if they feel these are more suitable to their specific observation. Furthermore, observers may also add brief comments concerning any of the items.

The third set of questions, inspired by the work of Vieira and colleagues (2004), and to be answered post-observation, invites the observer to compare the observed class with her/ his own classes, suggesting four guiding questions: What was most striking? What questions would I like to ask to my colleague? What similarities / differences were found in relation to my own lecturing practice? Can I make any suggestions? Finally, the fourth section covers impressions of the post-observation reflective discussion.

The lecturers anonymously insert the data from the observation forms in a website, thereby making such data available to the MPOT program's coordinators. At the end of each semester, findings from the data gathered online are publicly presented and discussed with the lecturers that participated in the program, as well as with all the academic community. From the first semester of 2012-2013 to the first semester of 2014-2015, 177 observation forms have been gathered, as outlined in

Previous studies established that this model of POT program can be valuable in stimulating the observer's comparisons between the observed practices and their own (Mouraz, Lopes, and Martins Ferreira 2013; Tenenberg 2014; Vieira et al. 2004), thus favoring reflection, self-motivation and self-confidence in experimenting new practices (Hendry, Bell, and Thomson 2014). And in fact, other analysis of data from this POT program have revealed that although this cannot have been an isolated driver of pedagogical change, it has favored individual changes in dimensions of teaching practices that can more easily be managed within the teachers autonomy, such as teachers' attitude and class organization (Reis, Sinde, and Pinto 2016).

\section{Methodology}

Aiming to address the pedagogical aspects to which lecturers paid more attention to in their class observations, an exploratory research study was conducted with data from the observation forms submitted from the first semester of 2012-2013 until the first semester of 2014-2015, and from interviews carried out between February and March 2014. Quantitative data refers to the scored items of the second set of questions in the

Table 2. Sample of observers that filled in the observation forms in a valid way, considering the disciplinary field of the observers.

\begin{tabular}{|c|c|c|c|c|c|c|}
\hline \multirow[b]{2}{*}{ Disciplinary field of the observer (code) [Faculties] } & \multicolumn{2}{|c|}{$\begin{array}{l}2012- \\
2013\end{array}$} & \multicolumn{2}{|c|}{$\begin{array}{c}2013- \\
2014\end{array}$} & \multirow{2}{*}{$\begin{array}{c}2014- \\
2015 \\
15\end{array}$} & \multirow{2}{*}{$\begin{array}{l}\text { TOTAL PER } \\
\text { FIELD }\end{array}$} \\
\hline & $1 S$ & $2 S$ & 1S & $2 S$ & & \\
\hline $\begin{array}{l}\text { Medical and Health Sciences (MHS) } \\
\text { [Sports, Nutrition and Food Science, Pharmacy, Dental Medicine, } \\
\text { Medicine, Biomedical Sciences] }\end{array}$ & 18 & 10 & 6 & 3 & 10 & 47 \\
\hline $\begin{array}{l}\text { Natural and Agricultural Sciences, Engineering and Technology (NASET) } \\
\text { [Sciences, Engineering] }\end{array}$ & 9 & 13 & 10 & 10 & 19 & 61 \\
\hline $\begin{array}{l}\text { Social Sciences and Humanities (SSH) } \\
\text { [Economics, Arts, Psychology and Education Sciences, Law, Business] }\end{array}$ & 15 & 18 & 18 & 10 & 8 & 69 \\
\hline $\begin{array}{l}\text { Fine Arts and Architecture (FAA) } \\
\text { [Architecture, Fine Arts] }\end{array}$ & 0 & 0 & 0 & 0 & 0 & 0 \\
\hline Total per semester & 42 & 41 & 34 & 23 & 37 & 177 \\
\hline
\end{tabular}


observation forms, and qualitative data to the observers' responses to the interviews and to the open question 'What was most striking?' of the observation forms.

In what regards the scored items of the observation forms, the main concern was to determine the number of items that were validly scored in each category, and not to measure the specific score given to the items. Therefore, the focus was on counting, for each item, the number of times in which a valid score (1 to 5) was assigned, as well as the number of times the item was not scored (missing answer and / or not applicable). The main purpose was not to evaluate whether an item was given a higher or lower score, but whether the lecturers felt that an item was present in their observation to such an extent that it deserved being scored, instead of being left blank.

A basic descriptive statistical analysis was performed on quantitative data with frequencies of scored and non-scored items using SPSS $\odot$.

A content analysis of the qualitative data from the observation forms and the interviews was performed using NVivo $\odot$. Units of analysis consisted on a sentence or a set of sentences in the lecturers' discourses that made sense as a whole to express a specific idea. These units of analysis were coded in predefined and emergent sub-categories grouped, whenever possible, within the categories defined in the observation forms. Absolute and relative frequencies were calculated for each sub-category, in order to allow a comparative analysis.

The qualitative data from the interviews and the observation forms were analysed and are presented separately, since they came from different datasets. Although informants from each of the two methods could sometimes be the same, the observation forms could not be matched with the interviews due to principles of anonymity and parity underlying the MPOT program and the observation forms' use. Moreover, while the observation forms provided more immediate, anonymous, shorter and class-specific post-observation perceptions, the interviews offered more long term, identifiable and in-depth perspectives. Indeed, the interviews often offered a broader explanation of the data in the observation forms.

\section{Findings}

In what concerns the pedagogical aspects to which lecturers pay more attention to in their class observations, the percentage of validly scored answers in each category of the second set of questions in the observation form is given in Figure 2, organized by disciplinary field, while Figure 3 provides information concerning the content analysis of the qualitative data from the observation forms, regarding what observers found more striking in their observations.

Lecturers consistently scored items in all categories. However, when asked in postobservation which pedagogical aspects were more striking, lecturers mostly mentioned items within the teachers' attitude and class climate. Table 3 presents absolute frequencies of sub-categories used to code qualitative data from the observations forms.

In post-observation, lecturers mentioned mostly the way observed colleagues communicated and interacted with students, as well as the students' engagement in the class. Lecturers also paid attention to the number of students in the class, noticing particularly numbers much higher or lower than those they are used to have in their own classes, and also to students' age differences and country of origin. 


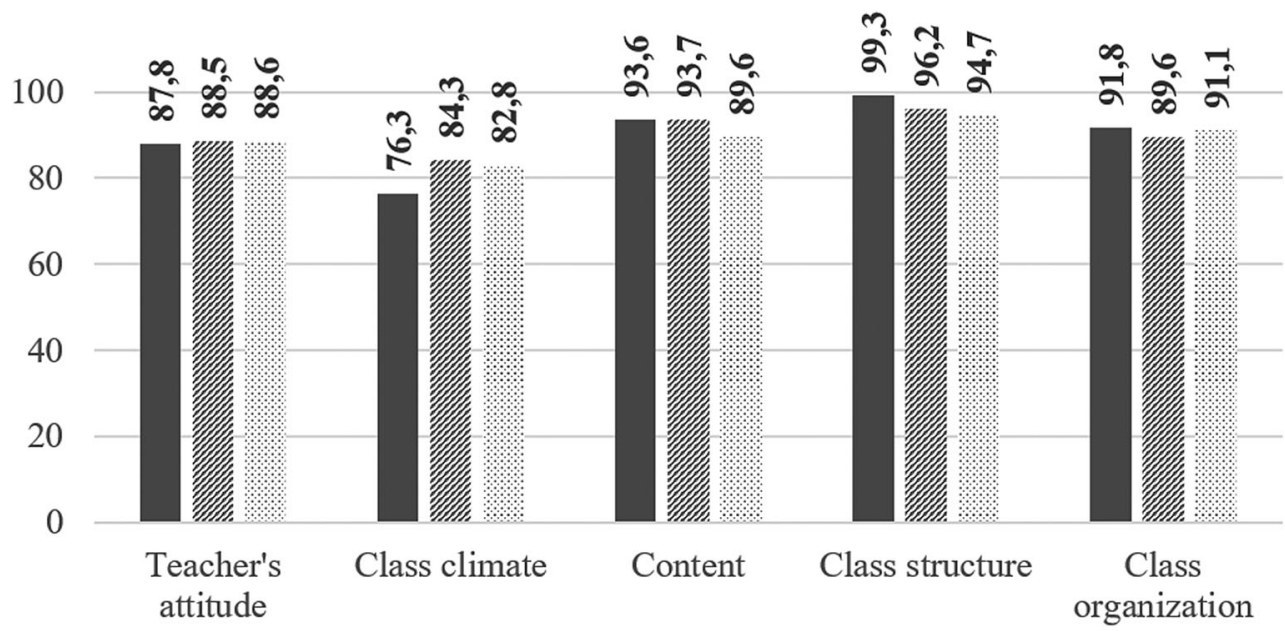

Medical and Health Sciences

\% Natural and Agricultural Sciences, Engineering and Technology

Social Sciences and Humanities

Figure 2. Percentage of validly scored answers in each category of the observation form per disciplinary field.

No major differences between the observers' disciplinary fields seem to exist. Instead, lecturers from all fields consistently emphasize communication and interaction with students, as well as students' engagement in the class. However, lecturers from Social Sciences and Humanities seem slightly more attentive to the lecturer's ability to monitor the

100

80

60

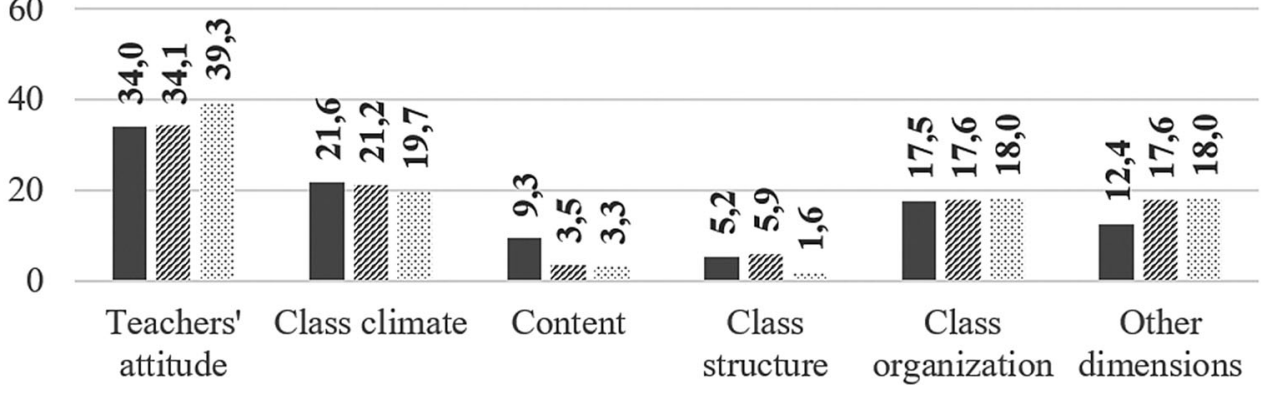

$\square$ Medical and Health Sciences

\% Natural and Agricultural Sciences, Engineering and Technology

: Social Sciences and Humanities

Figure 3. Percentage of references to pedagogical aspects that were the most striking, per category and disciplinary field of the observer. 
Table 3. Absolute frequencies per specific sub-category of pedagogical categories coded in the qualitative analysis of the observation forms.

\begin{tabular}{|c|c|}
\hline Sub-categories of pedagogical categories & Number of references \\
\hline TEACHERS' ATTITUDE & 83 \\
\hline Communication and interactions with students & 24 \\
\hline Appropriateness of the class rhythm & 17 \\
\hline Ability to make the class more motivating to students & 13 \\
\hline Posture, movement and proper use of voice and gestures & 7 \\
\hline Ability to monitor the progress of students & 7 \\
\hline Existence of systematization moments & 5 \\
\hline Attention to the overall dynamics of the group of students & 4 \\
\hline Focus on the class contents and tasks & 4 \\
\hline Promotion of the students' critical thinking & 2 \\
\hline CLASS CLIMATE & 51 \\
\hline Students' engagement in the class & 28 \\
\hline Students' behavior & 10 \\
\hline Participation in class previously prepared by students & 8 \\
\hline Collaboration between students & 5 \\
\hline CLASS ORGANIZATION & 43 \\
\hline Control and management of learning activities & 10 \\
\hline Adequacy of teaching strategies & 10 \\
\hline Adequacy of the lecture presentation & 9 \\
\hline Adequacy of classroom features (size, light, acoustics) & 9 \\
\hline Availability and use of equipment and other materials & 5 \\
\hline CONTENTS & 14 \\
\hline Contextualization of contents & 7 \\
\hline Use of examples & 5 \\
\hline Contents sequence & 2 \\
\hline CLASS STRUCTURE & 11 \\
\hline Identification of objectives in the class & 5 \\
\hline Clear objectives & 3 \\
\hline Clear class sequence & 3 \\
\hline OTHER CATEGORIES & 38 \\
\hline Features of the group of students & 19 \\
\hline Teachers' professional experience & 4 \\
\hline Challenging learning environment & 4 \\
\hline Students' assessment & 3 \\
\hline Preparation of the class & 3 \\
\hline Control of the students' attendance & 2 \\
\hline Adequacy of the class schedule & 2 \\
\hline Observers' interest in the contents & 1 \\
\hline
\end{tabular}

progress of students and to the focus in the class contents and tasks. On the other hand, lecturers from Medical Sciences appear to be more attentive to the class contents category than lecturers from other fields. Finally, the features of the groups of students in the class ('Other dimensions' in Figure 3) is somewhat more striking to lecturers from Natural Sciences and Engineering, and Social Sciences and Humanities, than to those from Medical Sciences.

In which concerns the interviews, Table 4 presents the categories used to code the qualitative data from the discourses and their absolute frequencies.

As in the observation forms, lecturers mentioned the way observed colleagues communicated and interacted with their students: 'The type of relationship the teacher could establish with the students (...) both verbal and non-verbal', the way the teacher 'interacted with his students', 'addressed the students' and 'relates himself with the audience, whatever the type of class (...), if there is an adjustment in the way he interacts with whom is listening to him'. 
Table 4. Number of comments, and interviewed lecturers that made them, per sub-category of pedagogical categories, coded in the qualitative analysis of the interviews.

\begin{tabular}{lcc} 
Sub-categories of pedagogical categories & $\begin{array}{c}\text { Number of } \\
\text { comments }\end{array}$ & $\begin{array}{c}\text { Number of interviewed lecturers that } \\
\text { referred to the sub-categories (out of 24) }\end{array}$ \\
\hline TEACHERS' ATTITUDE & 43 & 23 \\
Communication and interactions with students & 21 & 18 \\
Posture, movement and use of voice and gestures & 10 & 8 \\
Ability to make the class more motivating to students & 8 & 7 \\
Attention to the overall dynamics of the students & 3 & 3 \\
Ability to monitor the progress of students & 1 & 1 \\
CLASS CLIMATE & 27 & 15 \\
Students' engagement in the class & 14 & 10 \\
Students' behavior & 11 & 6 \\
Participation in class previously prepared by students & 1 & 1 \\
Collaboration between students & 1 & 1 \\
CLASS ORGANIZATION & 20 & 13 \\
Adequacy of the lecture presentation & 8 & 8 \\
Availability and use of equipment and other materials & 6 & 4 \\
Adequacy of teaching strategies & 3 & 3 \\
Adequacy of classroom features (size, light, acoustics) & 2 & 2 \\
CONTENTS & 3 & 3 \\
Contents sequence & 2 & 2 \\
Use of examples & 1 & 1 \\
CLASS STRUCTURE & 1 & 1 \\
Clear objectives & 1 & 1 \\
OTHER CATEGORIES & 12 & 10 \\
Observers' interest in the contents & 6 & 2 \\
Features of the group of students & 2 & 1 \\
Students' assessment & 2 & 2 \\
Preparation of the class & 1 & 1 \\
Control of the students' attendance & 1 & 2 \\
\hline
\end{tabular}

Similarly, the students' engagement in the class was again highly mentioned: 'the students' participation, the teacher being able to make the students more attentive and participative' and 'the students being quite attentive'.

In the interviews, lecturers tended more often to state that the posture, movement, voice and gestures of the observed lecturers was another aspect they paid attention to: 'the lecturers' posture, his position in the classroom, his voice tone', 'mimics, all that non spoken communication, non-verbalized, and the way the teacher moved in the classroom', 'the teacher turned his back to the audience, which has some risk when he had 100 persons watching his class'.

The lecturers' discourses in the interviews also showed some idiosyncrasies regarding the profiles of the students of some faculties, as illustrated by the quote 'depending on the faculty we go to, we have very attentive students and we have students that are doing other things'. For instance, Medicine students seem to be more engaged in the classes, as mentioned by a lecturer from the Faculty of Medicine:

In the classes that I observed, there was always a group of interested students, but then, there were others that we couldn't understand why they were even in there. (...) They didn't disturb the class. But it was a logic of students' interest different from the one I'm used to. It was that. (...) The students' participation and motivation was always something that I felt here. We, at Medicine, have a particular situation and a much higher obligation towards students. They don't come to this Faculty because they couldn't go to anywhere else. So, there is no reason for us to have uninterested students. 
Some remarks were also made concerning the type of knowledge and how it influences the type of class, though it quite often had more to do with class contents than with the faculty itself, as illustrated by this quote from a Faculty of Psychology and Education Sciences lecturer:

First, it was the way the lecturers dealt with the students' questions. (...) Than, it was the questions the lecturers posed that, to me, were quite strange and I couldn't understand because they were from other fields. It happened in Engineering. I remember that I observed a wonderful lesson about putting gutter in streets. And I had no idea that there was some science in gutters! I understood and I thought it was fantastic!

The interviews also revealed that observers tended to be attentive to pedagogical aspects that contrasted with, or seemed to be of concern in their own practices, particularly when they observed classes from a different faculty: 'I found some interest in the way the teacher conveyed the information and in the way he interacted with his students. As it was very different from what I was used to, it caught my attention', and 'I found to be quite interesting the committed collaboration between students, which is one thing that in my Faculty, maybe due to the nature of the knowledge, is not so clear. Our students participate a little less'.

Finally, discourses from the interviewed lectures also suggested engagement in processes of self-awareness as illustrated by this quote from a lecturer of Dental Medicine regarding an observation in the Faculty of Arts:

The high participation of students, because our classes are very different in that aspect. (...) I think that interacting more with students helps them a lot in their learning. As well as having a little bit more proximity to the students.

\section{Discussion}

Concerning what is seen by observers in a multidisciplinary POT program, presented findings show that although observers assigned a higher percentage of valid scores to observation form items within the class structure, content and class organization categories, they instead consistently stated, both in observation form comments and in the interviews, to have been mainly attentive to how the observed lecturers related themselves with the students in the class and to the students' engagement.

Indeed, and on the one hand, attention was given to the lecturers and how they interacted, communicated, stood in the classroom and stimulated motivation and participation. On the other hand, the focus was also on the students, particularly in their similarities/differences between fields and disciplines, how they shaped / were shaped by different academic cultures, engaged with the classes and the contents, and reacted to distinct strategies.

These findings are in line with those of Hendry, Bell, and Thomson (2014) related with observers' attention to students' reactions and level of engagement towards contextualized teaching practices. Contents and class structure were less mentioned in comments and interviews, while class organization was mostly focused on the specificities of the teaching strategies.

Naturally, one can argue that the lower emphasis on contents might simply be due to the multidisciplinary nature of the observations and with the fact that it is easier to comment on aspects that are of common concern across disciplines, such as 
communication, interaction and students' engagement. Nevertheless, it seems that observers are more at ease scoring items within contents, class structure and class organization since these aspects are almost taken for granted as shared by most higher education classes. Thus, when providing feedback, observers avoid addressing these aspects, thereby avoiding been seen as questioning the work of the observed colleague. Instead, as advocated by Hammersley-Fletcher and Orsmond (2004), this POT process, by confronting views from similar and different disciplines, allows observers to give more consideration to aspects of teaching and learning that go beyond 'the content and mechanics of the lesson being taught' (502) and to build critical and constructive feedback about pedagogical aspects that are also of their own concern.

These findings seem to support previous arguments (Kinchin 2005; Mouraz, Lopes, and Martins Ferreira 2013) that the multidisciplinary peer observation of teaching model presented can be useful in helping lecturers to move their focus from the contents being taught and into the pedagogical aspects that have been increasingly advocated as essential in quality teaching, that is, teacher-student interactions and relationships and students' motivation and engagement (Coates 2005; Hagenauer and Volet 2014; Knight and Trowler 2000). They also make us realize that our proposal of observation form serves its purpose of suggesting and guiding the class observation towards pedagogical aspects, but without restricting the observation to them. In fact, when asking observers to write about what was more striking in their class observations, and to compare the observed practices with their own, they often mentioned to 'observe what I probably try to put more attention to in my own classes', providing us with findings that also fall within the model of 'double-seeing' presented by Tenenberg (2014). While observing classes in different fields, or just discussing the observation with colleagues of different fields, the observer can also reflect about how certain attitudes and strategies work in terms of students' engagement, and imagine how they could be of use in her/his own classes, even if the contents are quite different.

Although there is not sufficient evidence to support that an actual critical reflection occurred, it seems that when lecturers are given the opportunity of observe classes from different disciplines they engage in processes of self-awareness (Cosh 1998) and come across with other ways of thinking, behaving and being a teacher (Kinchin 2005; Mouraz, Lopes, and Martins Ferreira 2013), favoring more openness, confidence and willingness for experimenting new strategies and styles, allowing learning opportunities for improved teaching.

Also, the program itself seems to be an important way of encouraging multi-faculty conversations that can 'significantly increase our understanding of what constitutes excellent teaching and how to measure it.' (Kohut, Burnap, and Yon 2007, 24).

Finally, we mention some limitations of this study. Although data was gathered from 177 observation forms, several of them can possibly refer to different observations from lecturers that participated more than once in the program. As the observation forms are anonymous, there is no way of determining the number of unique lecturers. However, we do know that an average of 24 lecturers participated in the program in each semester. This is the same as the number of interviewed lecturers, and also gives us a sample size comparable to the one in the study of observers' learning by Hendry, Bell, and Thomson (2014). 
Also, it was difficult to reliably explore possible differences between observations of lecturers from different faculties, given the relatively low number of University of Porto lecturers participating in the program (approximately 12\%). Should the participation increase in the future, this would provide sufficient data to address this topic in more detail.

\section{Conclusion}

Pedagogical features that 'caught the observers eye' in class observations within a multidisciplinary peer observation of teaching program concerned mainly aspects that allowed better teacher-students interactions and fostered students' motivation, engagement and independent learning. It is important to highlight that this was consistent among lecturers of all fields.

Similarly to what was reported in previous studies (Hendry, Bell, and Thomson 2014; Mouraz, Lopes, and Martins Ferreira 2013; Tenenberg 2014), lectures tended to compare observed teaching practices with their own. Being in a multidisciplinary environment, they also often compared features of class climate and its students between faculties. In line, findings also suggest that witnessing how the students reacted to these practices, observers developed self-awareness, confidence and enthusiasm for experimenting the new teaching styles and strategies they observed. And although previous analysis emerged from the impact study have only pointed out to effects in terms of actual changes in teachers' attitude and in class organization, as well as increment of pedagogical sensitivity and awareness of epistemic cultures of the different faculties (Reis, Sinde, and Pinto 2016), self-awareness, self-confidence and enthusiasm increase the likelihood of reflection and learning processes to occur.

We certainly agree that observing classes in the same field can bring important insights to one's teaching practices. And that's why observations within the same field are encouraged to some extent in our proposed model. However, our findings show that lecturers also engage in valuable learning opportunities even when they observe classes from different fields, or simply have the opportunity to discuss their observations with colleagues from different fields, since they move their focus from the class contents into pedagogical concerns they share with their observed colleagues, such as teachers' attitudes that foster students' engagement and learning.

Even if we acknowledge, as Hammersley-Fletcher and Orsmond (2005), that it is difficult to ensure that peer observation of teaching enables a truly critical reflection in the engaged lecturers, it seems as if there are key opportunities for the observers' learning that should not be disregarded, as they engage in a situation in which they can freely watch, listen and think about the teachers' and students' actions and reactions. This puts agency in the hands of the observer (Hendry, Bell, and Thomson 2014), empowering them to try new things, even if they only make slight changes at each time.

Furthermore, we agree with Thomson, Bell, and Hendry (2015) that removing the usual formalities of peer observation of teaching programs can be the most successful way to foster truly productive observations for both parts. From our experience, participation in the program, while voluntary, has been limited but steady, as many lecturers repeat their participation. And although the issue of being voluntary has been much debated many participant lecturers expressed that their non-participant colleagues should be 
required to participate at least once in the program -, this feature has remained as it seems to be essential to ensure parity, empathy, commitment and trust between the participants. The main problems seem to be institutional since lecturers who resist participating offer justifications such as limited time and lack of institutional recognition and rewards, in terms of professional career, for engaging in programs related to higher education pedagogy such as this one.

Therefore, we recommend that universities increasingly reward lecturers from all fields that assume a scholarly approach to their own teaching practices, for which peer observation programs can be enhancer devices. Finally, and as teacher-students relationships and students' engagement seem to be pedagogical concerns of increasing importance in lecturers from all disciplinary fields, this study's findings support the suggestions of Hagenauer and Volet (2014) regarding the need to fully integrate these pedagogical aspects in the larger body of research and discourse on the quality of teaching and learning in higher education.

\section{Acknowledgements}

The authors would like to express their gratitude to the University of Porto Rectorate, for supporting the 'Peer to Peer' program.

\section{Disclosure statement}

No potential conflict of interest was reported by the authors.

\section{Funding}

This work was funded by the Portuguese Calouste Gulbenkian Foundation under grant number 128176/2014 in Higher Education Development - Innovative Projects in the Educational Domain; and by the Portuguese Foundation for Science and Technology and General-Directorate of Higher Education under grant number 79/ID/2014 in Sharing and Dissemination of Innovative Educational Experiences among Portuguese Higher Education system.

\section{References}

Bell, M. 2001. "Supported Reflective Practice: A Programme of Peer Observation and Feedback for Academic Teaching Development." International Journal for Academic Development 6 (1): 29-39. doi:10.1080/13601440110033643.

Bell, A., and R. Mladenovic. 2015. "Situated Learning, Reflective Practice and Conceptual Expansion: Effective Peer Observation for Tutor Development." Teaching in Higher Education 20 (1): 24-36. doi:10.1080/13562517.2014.945163.

Coates, H. 2005. "The Value of Student Engagement for Higher Education Quality Assurance." Quality in Higher Education 11 (1): 25-36. doi:10.1080/13538320500074915.

Cosh, J. 1998. "Peer Observation in Higher Education - a Reflective Approach." Innovations in Education and Training International 35 (2): 171-176. doi:10.1080/1355800980350211.

Gosling, D. 2000. "Guidelines for Peer Observation of Learning and Teaching" King's College London: Notes prepared by Dr David Gosling for ESCalate Regional Networking Seminars. Accessed 3 June, 2016. https://www.kcl.ac.uk/study/learningteaching/kings/support/guidelinespeerobservation-dgosling.docx. 
Gosling, D. 2002. Models of Peer Observation of Teaching. Melbourne: LTSN Generic Centre in 2002 and presently Higher Education Academy. Accessed 3 June, 2016. http:// learningandteaching.vu.edu.au/teaching_practice/improve_my_teaching/evaluation_support_ for_my_teaching/Resources/id200_Models_of_Peer_Observation_of_Teaching.pdf.

Gosling, D. 2005. Peer Observation of Teaching. SEDA Paper 118. London: Staff and Educational Development Association Ltd.

Hagenauer, G., and S. E. Volet. 2014. “Teacher-student Relationship at University: An Important Yet Under-researched Field." Oxford Review of Education 40 (3): 370-388. doi:10.1080/ 03054985.2014.921613.

Hammersley-Fletcher, L., and P. Orsmond. 2004. "Evaluating Our Peers: Is Peer Observation a Meaningful Process?" Studies in Higher Education 29 (4): 489-503. doi:10.1080/ 0307507042000236380.

Hammersley-Fletcher, L., and P. Orsmond. 2005. "Reflecting on Reflective Practices within Peer Observation." Studies in Higher Education 30 (2): 213-224. doi:10.1080/03075070500043358.

Hendry, G. D., A. Bell, and K. Thomson. 2014. "Learning by Observing a Peer's Teaching Situation.” International Journal for Academic Development 19 (4): 318-329. doi:10.1080/ 1360144X.2013.848806.

Hénard, F. 2010. Learning Our Lesson: Review of Quality Teaching in Higher Education. Paris: OECD.

Kinchin, I. M. 2005. “Evolving Diversity within a Model of Peer Observation at a UK University.” In British Educational Research Association (BERA) Annual Conference, University of Glamorgan, Wales, 14-17. http://www.leeds.ac.uk/educol/documents/153411.doc.

Knight, P., and P. Trowler. 2000. "Departmental-level Cultures and the Improvement of Learning and Teaching." Studies in Higher Education 25 (1): 69-83. doi:10.1080/030750700116028.

Kohut, G. F., C. Burnap, and M. G. Yon. 2007. "Peer Observation of Teaching: Perceptions of the Observer and the Observed." College Teaching 55 (1): 19-25. doi:10.3200/CTCH.55.1.19-25.

Lomas, L., and G. Nicholls. 2005. "Enhancing Teaching Quality Through Peer Review of Teaching." Quality in Higher Education 11 (2): 137-149. doi:10.1080/13538320500175118.

Martin, G., and J. Double. 1998. "Developing Higher Education Teaching Skills Through Peer Observation and Collaborative Refection." Innovations in Education and Training International 35 (2): 161-170. doi:10.1080/1355800980350210.

Martsolf, D. S., B. C. Dieckman, K. A. Cartechine, P. J. Starr, L. E. Wolf, and E. R. Anaya. 1999. "Peer Review of Teaching: Instituting a Program in a College of Nursing." Journal of Nursing Education 38 (7): 326-332.

McMahon, T., T. Barrett, and G. O’Neill. 2007. “Using Observation of Teaching to Improve Quality: Finding Your Way Through the Muddle of Competing Conceptions, Confusion of Practice and Mutually Exclusive Intentions." Teaching in Higher Education 12 (4): 499-511. doi:10.1080/13562510701415607.

Mouraz, A., A. Lopes, and J. M. Martins Ferreira. 2013. "Higher Education Challenges to Teaching Practices: Perspectives Drawn from a Multidisciplinary Peer Observation of Teaching Program." International Journal of Advanced Research 1 (6): 377-386.

Reis, A., Sinde, M. R., and Pinto, D. 2016. "Efeitos da observação de pares multidisciplinar no ensino superior: uma perspetiva focada no observador [Effects of Multidisciplinary Peer Observation in Highers Education: A Perspective Focused on the Obsever]." In La docencia universitaria: desafios y perspectivas [University Teaching: Challenges and perspectives], edited by Pedro Membiela, Natalia Casado, Maria Isabel Cebreiros, 139-143. Ourense: Educación Editora.

Tenenberg, J. 2014. "Learning Through Observing Peers in Practice." Studies in Higher Education 41 (4): 756-773. doi:10.1080/03075079.2014.950954.

Thomson, K., A. Bell, and G. Hendry. 2015. "Peer Observation of Teaching: the Case for Learning Just by Watching." Higher Education Research \& Development 34 (5): 1060-1062. doi:10.1080/ 07294360.2015.1034349.

Veiga, A., and A. Amaral. 2009. "Survey on the Implementation of the Bologna Process in Portugal.” Higher Education 57 (1): 57-69. doi:10.1007/s10734-008-9132-6. 
Vieira, F. 2005. "Transformar a Pedagogia na Universidade? [Transforming Pedagogy in the University]." Currículo sem fronteiras [Curriculum without Frontiers] 5 (1): 10-27.

Vieira, F., J. L. Silva, M. C. Melo, M. A. Moreira, L. R. Oliveira, C. Gomes, P. B. Albuquerque, and M. Sousa. 2004. Transformar a pedagogia na universidade: Experiências de investigação do ensino e da aprendizagem [Transforming Pedagogy in the University: Teaching and Learning Research Experiences]. Braga: Universidade do Minho, CIEd.

Yiend, J., S. Weller, and I. Kinchin. 2014. "Peer Observation of Teaching: The Interaction Between Peer Review and Developmental Models of Practice." Journal of Further and Higher Education 38 (4): 465-484. doi:10.1080/0309877X.2012.726967. 